\title{
Feasibility of personalized screening and prevention recommendations in the general population through breast cancer risk assessment: results from a dedicated risk clinic
}

\author{
Mahasti Saghatchian ${ }^{1,5}$ (1) Marc Abehsera ${ }^{1} \cdot$ Amina Yamgnane $^{1} \cdot$ Caroline Geyl $^{1} \cdot$ Emilien Gauthier $^{2}$. \\ Valérie Hélin ${ }^{2} \cdot$ Matéo Bazire $^{3} \cdot$ Laure Villoing-Gaudé $^{3}$. Cécile Reyes $^{3} \cdot$ David Gentien $^{3} \cdot$ Lisa Golmard $^{4}$. \\ Dominique Stoppa-Lyonnet ${ }^{3,4}$
}

Received: 22 July 2021 / Accepted: 8 November 2021 / Published online: 7 January 2022

(c) The Author(s), under exclusive licence to Springer Science+Business Media, LLC, part of Springer Nature 2022

\begin{abstract}
Purpose A personalized approach to prevention and early detection based on known risk factors should contribute to early diagnosis and treatment of breast cancer. We initiated a risk assessment clinic for all women wishing to undergo an individual breast cancer risk assessment.

Methods Women underwent a complete breast cancer assessment including a questionnaire, mammogram with evaluation of breast density, collection of saliva sample, consultation with a radiologist, and a breast cancer specialist. Women aged 40 or older, with 0 or 1 first-degree relative with breast cancer diagnosed after the age of 40 were eligible for risk assessment using MammoRisk, a machine learning-based tool that provides an individual 5-year estimated risk of developing breast cancer based on the patient's clinical data and breast density, with or without polygenic risk scores (PRSs). DNA was extracted from saliva samples for genotyping of 76 single-nucleotide polymorphisms. The individual risk was communicated to the patient, with individualized screening and prevention recommendations.

Results A total of 290 women underwent breast cancer assessment, among which 196 women (68\%) were eligible for risk assessment using MammoRisk (median age 52, range 40-72). When PRS was added to MammoRisk, 40\% ( $n=78$ ) of patients were assigned a different risk category, with $28 \%(n=55)$ of patients changing from intermediate to moderate or high risk. Conclusion Individual risk assessment is feasible in the general population. Screening recommendations could be given based on individual risk. The use of PRS changed the risk score and screening recommendations in $40 \%$ of women.
\end{abstract}

Keywords Breast cancer $\cdot$ Risk assessment $\cdot$ Screening $\cdot$ Polygenic risk score $\cdot$ Mammographic density

\section{Introduction}

Breast cancer death rates have been decreasing in the past 20 years in most European countries [1,2], due to earlier detection and improved treatments. Mammographic

Mahasti Saghatchian

mahasti.saghatchian@ahparis.org

American Hospital of Paris, Neuilly-sur-Seine, France

Predilife, Villejuif, France

Institut Curie, Paris, France

4 INSERM U830 D.R.U.M. Team, Institut Curie Hospital, Paris-University, Paris, France

5 Paris-Descartes University, Paris, France screening has been shown to reduce death from breast cancer by approximately $20 \%$ [3]. In France, biennial mammographic screening is recommended for women aged 50-74 years without specific high risk, although the risk of developing cancer varies among average-risk women according to known risk factors, such as mammographic breast density, family history of breast or ovarian cancer, endocrine exposures, lifestyle patterns, and history of benign breast disease [4-8]. Breast density has been shown to be a strong risk factor for breast cancer, as women with very dense breasts are as much as 4-6 times more likely to develop breast cancer than those with low breast density [9-13]. In addition, genome-wide association studies (GWAS) have identified common genetic variants, mostly single-nucleotide polymorphisms (SNPs) known to increase breast cancer risk. Although each variant only confers a small risk, their 
combination in a polygenic risk score (PRS) are predictive of the risk of developing cancer in those without a family history [14-16]. A personalized approach to prevention and early detection based not only on age but also on various risk factors is a promising strategy, as it should adapt the screening intervals and modalities depending on the woman's individual risk and contribute to early diagnosis and treatment of breast cancer at an early and curable stage [8].

Several risk prediction models have been developed based on known risk factors, such as Gail [17, 18], Claus [19], BRCAPRO [20], Tyrer-Cuzick [21], and the Breast and Ovarian Analysis of Disease Incidence and Carrier Estimation Algorithm (BOADICEA) [22-26] models. The addition of breast density and PRSs has been shown to improve the performance of existing breast cancer risk prediction tools in the general population [27-30]. Lifestyle-related factors are also associated with breast cancer risk and are actionable, in contrast to family history, breast density, or SNPs. It has been shown that an overall healthy lifestyle may reduce the impact of genetic risk factors on breast cancer [31]. Individualized risk assessment may also be an opportunity to advise women on a healthier lifestyle. However, data are still limited on the feasibility of individual risk assessment in the general population of women undergoing routine screening mammography.

Since January 2019, we have implemented a risk assessment clinic for all women wishing to undergo an individual breast cancer risk assessment. We report here our experience using a risk assessment tool targeted for presumed average-risk women. We also assessed whether PRS changed the risk classification in our study sample.

\section{Patients and methods}

\section{Patients}

The risk assessment clinic was open to all women wishing to have their individual risk assessed. For women without specific known high risk, the risk assessment tool MammoRisk (Predilife, Villejuif, France) was used. Women aged 40 or older, with no more than one first-degree relative with breast cancer diagnosed after the age of 40 were eligible for risk assessment using MammoRisk. Women previously identified as high risk, those who received chest irradiation (Hodgkin's disease), those with a personal history of breast cancer, atypical hyperplasia, or lobular carcinoma in situ, and those with a strong family history of breast or ovarian cancer (Fig. 1) were not eligible for risk assessment using MammoRisk. For those with a strong family history of breast cancer, a genetic consultation was proposed and other risk assessment tools (Tyrer-Cuzick or BOADICEA) were used, depending on the Eisinger score [32].

\section{Patient pathway}

Women scheduled an appointment at the Women's Risk Institute at the American Hospital of Paris and underwent

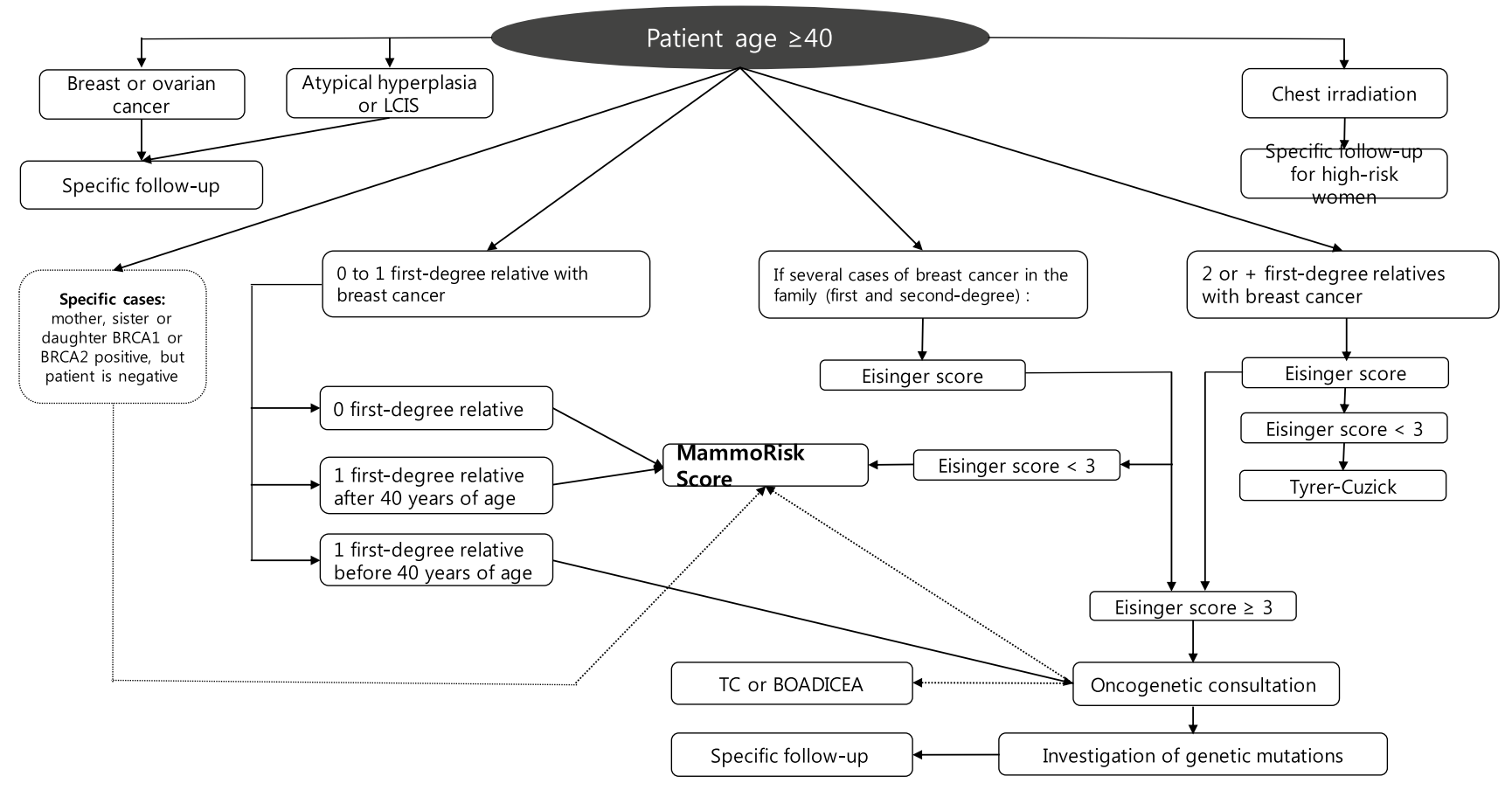

Fig. 1 Risk assessment flowchart. LCIS lobular carcinoma in situ 
a complete breast cancer assessment, including a questionnaire, mammogram with evaluation of breast density, consultation with a radiologist who explained the mammogram and risk assessment, and a breast cancer specialist. The breast cancer specialist was either a medical oncologist, a gynecologist, or a general practitioner trained in breast cancer care. Women came on their own initiative were referred by their physician or gynecologist or found out about the risk assessment clinic through annual check-up programs offered by their employers or health insurance. The complete breast cancer assessment took about $2 \mathrm{~h}$ per patient in a dedicated area. The patient was guided by a nurse navigator throughout the process. Women who were eligible for risk assessment using MammoRisk also provided their saliva sample during the visit for PRS assessment. All patients provided written consent form.

The visit concluded with a consultation with a breast cancer specialist for a clinical examination, lifestyle questionnaire review, explanation about risk factors, how risk score is calculated using MammoRisk, and general prevention recommendations. Three weeks after the appointment, the content of the MammoRisk report based on the individual 5 -year estimated risk was communicated to the patient by mail, phone, or teleconsultation, depending on the patient's request. The report included a personal risk assessment, comparison with the general population, individualized screening program and prevention recommendations, in terms of diet, physical activity, alcohol consumption, and hormonal treatments (birth control and menopause hormone replacement therapy)(Report examples are shown in Supplementary Fig. 1).

The complete pathway could also be proposed remotely, in which case following a first teleconsultation with a nurse who fills the questionnaire and provides explanation on the self-collection of saliva, the saliva collection kit was sent to the patient. The patient then sent the self-collected saliva, a recent ( $<1$ year) mammogram report, mammograms, and consent form. The MammoRisk report with screening and prevention recommendations was communicated to the patient in a second teleconsultation with a breast cancer specialist.

Appointments for subsequent screening follow-up were made on patient's request.

\section{PRS}

DNA was extracted from saliva samples for genotyping of 76 SNPs using TaqMan® SNP Genotyping Assay [33]. The PRS was calculated using published per-allele odds ratio corresponding to the SNP associations with breast cancer. As the PRSs have only been validated in women of Caucasian ancestry [14, 33-38], it was incorporated in MammoRisk only for women of Caucasian origin.

\section{Risk assessment}

MammoRisk is a machine learning-based risk assessment tool developed on the US Breast Cancer Screening Consortium (BCSC) cohort [39-41] that provides an individual 5-year estimated risk of developing breast cancer based on four characteristics (the patient's age, family history of breast cancer, history of breast biopsies, breast density), with or without PRS. This tool was shown to provide similar discrimination (area under the curve for discrimination of $0.659,95 \%$ confidence interval [CI] 0.65-0.67 vs. $0.656,95 \%$ CI $0.65-0.66$ for BCSC), and calibration (ratio of expected to observed breast cancer cases 1.00, 95\% CI $0.98-1.02$ vs. $0.94,95 \%$ CI $0.92-0.96$ for BCSC) to the BCSC model on the BCSC cohort [42]. Along with the Tyrer-Cuzick score and the PRS based on 313 breast cancer-associated variants, it is used as a component of the risk assessment platform of MyPeBS, a multi-country randomized trial of personalized breast cancer screening in Europe [43]. Breast density was estimated using a software tool, DenSeeMammo (Predilife, Villejuif, France) [44]. MammoRisk and DenSeeMammo are both manufactured by the same company. The risk score with PRS was communicated to the patients. For women of other ethnicities, PRS was only analyzed for investigational purposes and not used for actual risk assessment. We report here only on those who underwent risk assessment using MammoRisk with PRS.

The risk at 5 years was classified into four categories established based on available guidelines [43]: moderate risk, $<1 \%$, intermediate risk, $1-1.66 \%$, high risk, $1.67-5.99 \%$, and very high risk $\geq 6 \%$. The recommendations by default for each category were as follows, but were adapted to the benefit and risk assessment of each patient by the breast cancer specialist: for moderate risk, mammography exam every 2 years and ultrasound if breast density $\mathrm{C}$ or $\mathrm{D}$ from age 50; for intermediate risk, mammography exam every 2 years and ultrasound if breast density C or D from age 40; for high risk, mammography exam every year and ultrasound if breast density $\mathrm{C}$ or D from age 40; and for very high risk, mammography exam and magnetic resonance imaging (MRI) every year from age 40. An annual clinical examination was recommended regardless of the risk category.

Patients directed to oncogenetic consultation were proposed a multigene panel test, including $B R C A 1 / 2$. If a mutation in one of the genes of the panel was detected, then specific recommendations were discussed with the patient. If not, the woman's risk was evaluated using Tyrer-Cuzick or BOADICEA risk scores and specific recommendations were proposed according to the result. 


\section{Statistical analysis}

We compared the risk category assigned to each woman using MammoRisk with and without PRS and analyzed whether the use of PRS modified clinical recommendations.

\section{Results}

\section{Patient characteristics}

A total of 290 women underwent breast cancer assessment between January 2019 and May 2021. Analysis was performed on 196 women (68\%) who were eligible for risk assessment using MammoRisk with PRS. Ninety-four women were not eligible for risk assessment using MammoRisk with PRS for the following reasons: less than 40 years of age $(n=12)$, history of atypical hyperplasia $(n=2)$, directed to oncogenetic consultation $(n=13)$, nonCaucasian origin $(n=35)$, or considered for Tyrer-Cuzick risk assessment $(n=32)$. The patient characteristics of the 196 women who underwent risk assessment using MammoRisk are shown in Table 1.

\section{Risk assessment}

Following risk assessment using MammoRisk without PRS, $16 \%(n=32)$ were classified as moderate risk $(<1 \%)$, 53\% $(n=103)$ as intermediate risk ( $\geq 1$ and $<1.67 \%), 31 \%$ $(n=61)$ as high risk $(\geq 1.67$ and $<6 \%)$, and $0 \%(n=0)$ as very high risk $(\geq 6 \%)$. Median risk score (estimated risk at 5 years) was 1.5 (range $0.3-3.7$ ). When PRS was added to MammoRisk, 25\% $(n=48)$ were classified as moderate risk

Table 1 Patient characteristics $(n=196)$

\begin{tabular}{lc}
\hline Characteristics & \\
\hline Median age (min; max) & $52(40-72)$ \\
History of benign breast biopsy $(n, \%)$ & $26(13.3)$ \\
Yes & $170(86.7)$ \\
No & \\
Family history of breast cancer* $(n, \%)$ & $130(66.3)$ \\
0 & $63(32.1)$ \\
1 & $3(1.5)$ \\
2 and more & \\
Breast density $(n, \%)$ & $6(3.1)$ \\
$A$ & $51(26.0)$ \\
$B$ & $114(58.2)$ \\
$C$ & $25(12.8)$ \\
$D$ &
\end{tabular}

*First-degree family history, except for "2 and more," which refers to first- and second-degree relatives
$(<1 \%), 33 \%(n=65)$ as intermediate risk $(\geq 1$ and $<1.67 \%)$, $42 \%(n=83)$ as high risk $(\geq 1.67$ and $<6 \%)$, and $0 \%(n=0)$ as very high risk ( $\geq 6 \%$ ), and corresponding screening and prevention recommendations were given to the patients. Median risk score with PRS was 1.5 (range 0.2-4.7). The proportions of patients in each risk category assigned by MammoRisk with and without PRS are shown in Fig. 2.

A total of $40 \%(n=78)$ of patients were assigned a different risk category when PRS was added to MammoRisk. Importantly, 28\% $(n=55)$ of patients changed from intermediate risk to moderate or high risk. The distribution of the risk scores with and without PRS are shown in Fig. 3. Analysis showed that PRS was independent of family history and breast density (Figs. 4, 5). Twenty-four patients (8 patients when not using PRS) had a 5-year risk of $\geq 3 \%$, a threshold for chemoprevention in the USA. [45].

\section{Discussion}

We reported here the feasibility of a risk assessment clinic in the general population. Screening recommendations could be given based on individual risk. The use of PRS changed the risk score and monitoring and prevention recommendations in $40 \%$ of women, $28 \%$ being classified from intermediate to moderate or high risk.

Depending on the calculated risk, types and frequencies of screening exams that were adapted to individual risk could be recommended to the patients, which could be biennial mammography from age 50 for women with moderate risk and annual mammography and ultrasound for high-risk women. A regular examination by the gynecologist was recommended to all women regardless of their risk category, and modifiable lifestyle factors were discussed. Patients were also explained that their risk will change over time and that any new event may change their risk and individualized screening recommendations, which should

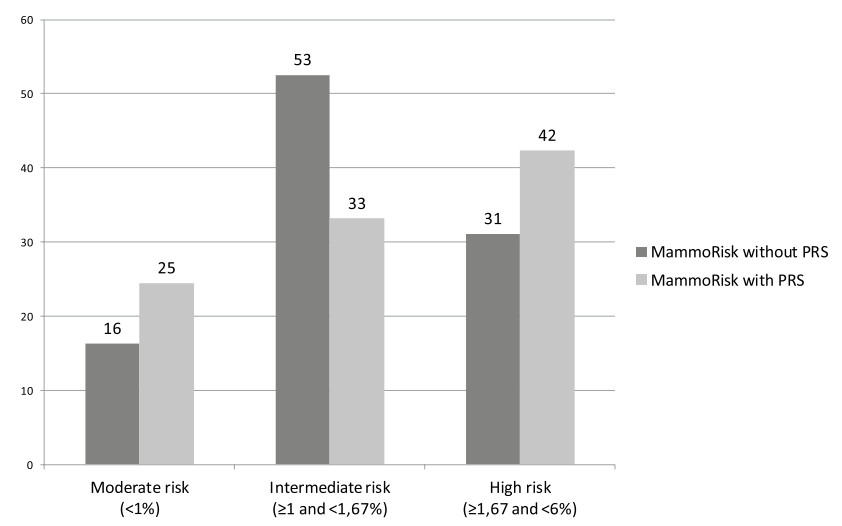

Fig. 2 Proportions of patients assigned to risk categories using MammoRisk with and without PRS (\%) 
Fig. 3 Distribution of risk scores with and without PRS
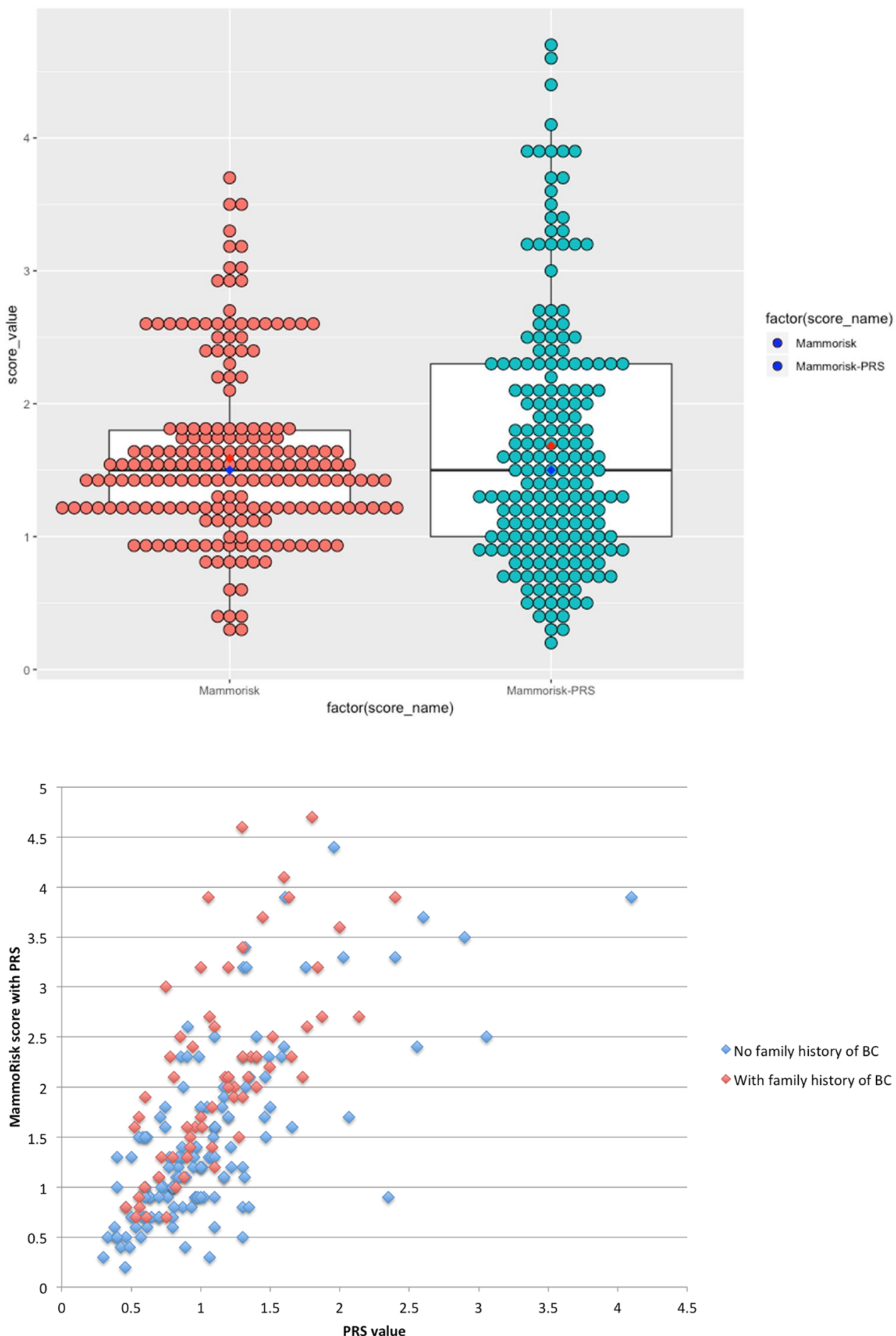

Fig. 4 PRS and risk scores according to family history of breast cancer be reviewed at least every 5 years (See Supplementary Fig. 1). When patients were found to be at high risk, additional exams could be performed. We had a case of a patient who could have a diagnosis made at an early stage because she was assessed to be at high risk using MammoRisk: the gynecologist performed a careful clinical examination at the follow-up visit 1 year after risk assessment and detected a small swelling in the axilla with a benign appearance, which appeared as a benign swelling on mammogram and ultrasound. This would normally not have led to further investigation, but because of her high risk, an axillary biopsy was performed and confirmed a positive axillary lymph node with grade 3 invasive ductal carcinoma, triple negative. MRI confirmed a $3 \mathrm{~mm}$ lump in the breast. Because of personalized risk assessment, diagnosis could be made at a very early stage. We have also had patients less than 50 years of age 
Fig. 5 PRS and risk scores according to breast density

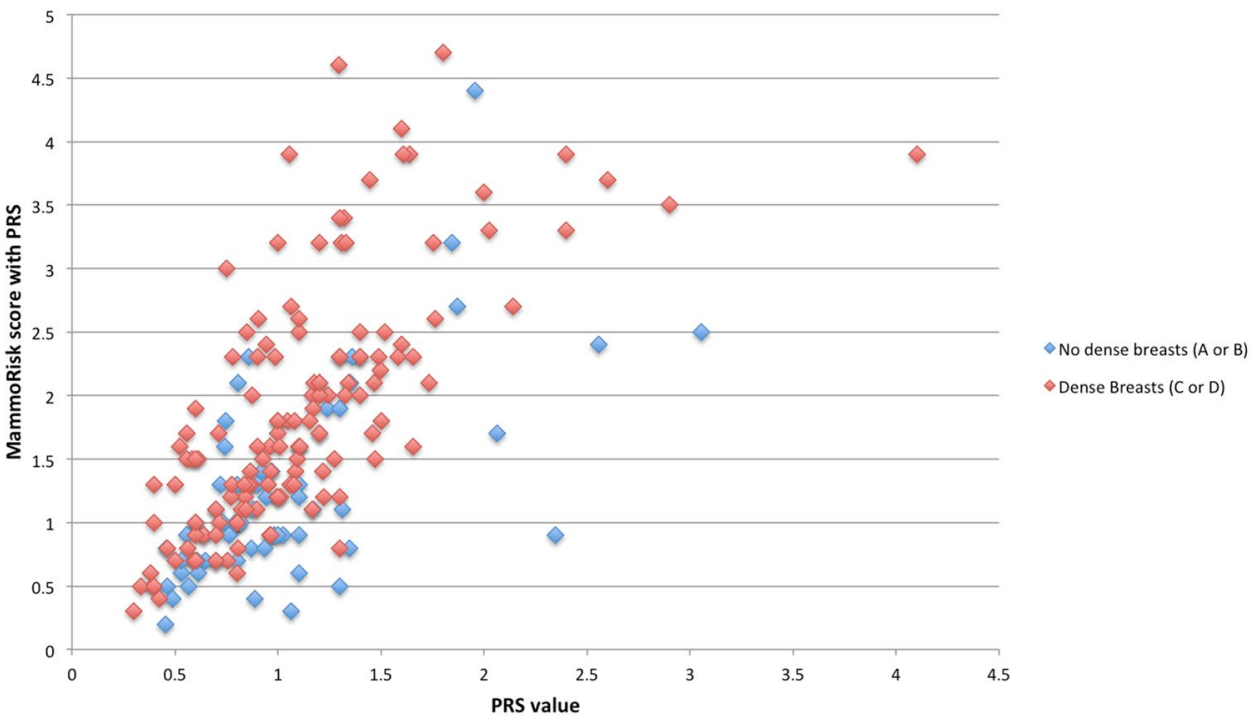

assessed to be at moderate risk, to whom we could safely say that their risk scores do not justify beginning screening exam before the age of 50 and recommend a screening exam every 2 years from the age of 50 .

Many patients came on their own initiative, wishing to know their individual risk and have personalized prevention measures, especially regarding hormonal treatments (birth control or menopause hormone replacement therapy). For intermediate to high-risk patients, non-hormonal options were recommended. Other patients found out about the risk assessment clinic through the hospital's imaging department and gynecologists. However, there needs to be even more information and communication on the program and the existence of preventive measures. Overall, the methodology of evaluating individual risk was well understood by the patients, who were very interested in the means to control the risk, especially in terms of diet. There was a need to clearly explain the difference, however, between the individual genetic risk (PRS) and hereditary risk (e.g., BRCA), especially to those with a family history of cancer. Patients classified as high risk understood the need for close surveillance. The patient pathway was smooth and did not require adjustments. Of note, risk assessment was conducted remotely in about $10 \%$ of patients, which was in demand especially since the beginning of the COVID-19 pandemic.

Individual risk assessment consultations in the general population have been reported using different risk assessment tools. The Riviera study (NCT02997384) [46] evaluated the feasibility of a consultation dedicated to informing women about their risk of breast cancer and screening recommendations during a routine consultation at a general practitioner, a gynecologist, or a radiologist, using MammoRisk, in France. Ninety-seven percent of women $(n=434)$ accepted to have their risk assessment, indicating that personalized risk assessment and delivery of screening recommendations were feasible in community practices and accepted by the majority of patients and anxiety at $48 \mathrm{~h}$ was limited. A recent report from a hospital in France, which has been implementing a risk assessment consultation for all women aged 18 and older using the Tyrer-Cuzick model and MammoRisk, reported their initial experience on 164 women. Sixty percent of women had a change in screening methods following risk assessment and $98 \%$ reported to be satisfied or very satisfied with the consultation [47].

This study has several limitations. This is a singlecenter experience with a small sample size. In addition, women attending the risk assessment clinic, either on their own initiative or upon recommendation by their medical practitioner, tended to present more risk factors (previous breast biopsies, family history of breast cancer). Indeed, among those who underwent risk assessment using MammoRisk, the proportions of women who had a previous benign breast biopsy and those with a first-degree family history of breast cancer were higher (26\% vs. $6 \%$ and $63 \%$ vs. $11 \%$, respectively) compared to a French screening cohort [42]. Also, 19\% of women aged 40 or older were not eligible for MammoRisk, as they either had a history of atypical hyperplasia or a strong family history, which is likely much higher than the proportion in the general population. The findings may therefore not be generalizable to the general population. Nevertheless, it shows that personalized risk assessment meets a real need for those who are aware of their breast cancer risk and wish concrete screening and prevention recommendations. Also, we did not use different risk assessment tools in this study to compare the estimates, as the study's objective was to assess the feasibility of a risk assessment clinic using one tool for each target population. Another study used MammoRisk and Tyrer-Cuzick for a proportion of patients and found that the assigned risk category was the same in $39 \%$ 
and higher using Tyrer-Cuzick in 51\% of patients [47]. The performance of different assessment tools should be further investigated. Another limitation is that the analysis on PRS was restricted to women of Caucasian origin, as the PRS used in MammoRisk has only been validated in women of European ancestry [14, 33-38]. Women of other ethnicities had their individual risk assessed and were given personalized recommendations, but without PRS.

Population-specific PRSs are currently developed with data from ongoing large-scale GWAS for improved risk assessment in women of ethnicities other than European ancestry [48-50] and may be integrated in the risk assessment tool in the future. The software tool is flexible and can incorporate additional risk factors and can easily be updated as new data become available. The risk classification may then further be refined, as on one side, new variants are discovered improving the predictive value of PRSs and on the other side, deleterious mutations of the multigene panel, which are not so rare ( 1 out of 200 to 400 women in the general population [51, 52]), can also be included in risk scores for the general population.

Tools are now available to perform individual risk assessment and propose personalized screening and prevention recommendations. The risk assessment consultation is also an excellent opportunity to discuss with the patient on modifiable lifestyle risk factors, such as alcohol consumption, diet, and physical activity, which are also valid for the prevention of other diseases. Although a 2-h pathway involving a radiologist, breast specialist, and nurse navigator may not be feasible in all hospital settings, such risk assessment clinics would make the shift from treatment-oriented care to prevention, early diagnosis, and health promotion. While we show that individual risk assessment is feasible in the setting of a specialized clinic, population-level studies are needed to assess its clinical utility, whether it contributes to early detection and decrease in incidence of advanced-stage disease and whether it is cost effective and acceptable to patients of all socio-economic groups. This is expected to be clarified with results from large clinical studies evaluating the efficacy, safety, and acceptability of personalized breast cancer screening compared to the age-based screening ongoing in the USA (WISDOM study, NCT02620852) [53], Canada (Perspective study) [54], and Europe (MyPeBS study, NCT03672331) [43].

Supplementary Information The online version contains supplementary material available at https://doi.org/10.1007/s10549-021-06445-8.

Funding AstraZeneca is funding the French COVAR study coordinated by Institut Curie, which aims to classify BRCA1/2 Variants of Unknown Significance. The Department of Genetics, Institut Curie is performing the genotyping (PRS) for MammoRisk ${ }^{\circledR}$ (Predilife). Dominique Stoppa-Lyonnet and Institut Curie have received honoraria for their participation in educational meetings organized by AstraZeneca and Tesaro. No funds, grants, or other support were received for this study.

\section{Declarations}

Conflict of interest Mahasti Saghatchian has received speaker honorarium from Predilife, the company commercializing MammoRisk. Other authors have no conflict of interest to declare that are relevant to the content of this article.

\section{References}

1. Carioli G, Malvezzi M, Rodriguez T, Bertuccio P, Negri E, La Vecchia C (2017) Trends and predictions to 2020 in breast cancer mortality in Europe. Breast 36:89-95

2. Malvezzi M, Carioli G, Bertuccio P, Boffetta P, Levi F, La Vecchia $\mathrm{C}$ et al (2019) European cancer mortality predictions for the year 2019 with focus on breast cancer. Ann Oncol 30(5):781-787

3. Marmot MG, Altman DG, Cameron DA, Dewar JA, Thompson SG, Wilcox M (2013) The benefits and harms of breast cancer screening: an independent review. Br J Cancer 108(11):2205-2240

4. Hartmann LC, Sellers TA, Frost MH, Lingle WL, Degnim AC, Ghosh $\mathrm{K}$ et al (2005) Benign breast disease and the risk of breast cancer. N Engl J Med 353(3):229-237

5. Nelson HD, Zakher B, Cantor A, Fu R, Griffin J, O’Meara ES et al (2012) Risk factors for breast cancer for women aged 40 to 49 years: a systematic review and meta-analysis. Ann Intern Med 156(9):635-648

6. Pankratz VS, Degnim AC, Frank RD, Frost MH, Visscher DW, Vierkant RA et al (2015) Model for individualized prediction of breast cancer risk after a benign breast biopsy. J Clin Oncol 33(8):923-929

7. Winters S, Martin C, Murphy D, Shokar NK (2017) Breast cancer epidemiology, prevention, and screening. Prog Mol Biol Transl Sci 151:1-32

8. Pashayan N, Antoniou AC, Ivanus U, Esserman LJ, Easton DF, French D et al (2020) Personalized early detection and prevention of breast cancer: ENVISION consensus statement. Nat Rev Clin Oncol 17(11):687-705

9. Harvey JA, Bovbjerg VE (2004) Quantitative assessment of mammographic breast density: relationship with breast cancer risk. Radiology 230(1):29-41

10. Vacek PM, Geller BM (2004) A prospective study of breast cancer risk using routine mammographic breast density measurements. Cancer Epidemiol Biomark Prev 13(5):715-722

11. Boyd NF, Rommens JM, Vogt K, Lee V, Hopper JL, Yaffe MJ et al (2005) Mammographic breast density as an intermediate phenotype for breast cancer. Lancet Oncol 6(10):798-808

12. McCormack VA, dos Santos SI (2006) Breast density and parenchymal patterns as markers of breast cancer risk: a meta-analysis. Cancer Epidemiol Biomark Prev 15(6):1159-1169

13. Boyd NF, Guo H, Martin LJ, Sun L, Stone J, Fishell E et al (2007) Mammographic density and the risk and detection of breast cancer. N Engl J Med 356(3):227-236

14. Mavaddat N, Michailidou K, Dennis J, Lush M, Fachal L, Lee A et al (2019) Polygenic risk scores for prediction of breast cancer and breast cancer subtypes. Am J Hum Genet 104(1):21-34

15. Mavaddat N, Pharoah PD, Michailidou K, Tyrer J, Brook MN, Bolla MK et al (2015) Prediction of breast cancer risk based on profiling with common genetic variants. J Natl Cancer Inst. https:// doi.org/10.1093/jnci/djv036

16. Zhang H, Ahearn TU, Lecarpentier J, Barnes D, Beesley J, Qi G et al (2020) Genome-wide association study identifies 32 novel 
breast cancer susceptibility loci from overall and subtype-specific analyses. Nat Genet 52(6):572-581

17. Gail MH, Brinton LA, Byar DP, Corle DK, Green SB, Schairer C et al (1989) Projecting individualized probabilities of developing breast cancer for white females who are being examined annually. J Natl Cancer Inst 81(24):1879-1886

18. Costantino JP, Gail MH, Pee D, Anderson S, Redmond CK, Benichou J et al (1999) Validation studies for models projecting the risk of invasive and total breast cancer incidence. J Natl Cancer Inst 91(18): 1541-1548

19. Claus EB, Risch N, Thompson WD (1991) Genetic analysis of breast cancer in the cancer and steroid hormone study. Am J Hum Genet 48(2):232-242

20. Parmigiani G, Berry D, Aguilar O (1998) Determining carrier probabilities for breast cancer-susceptibility genes BRCA1 and BRCA2. Am J Hum Genet 62(1):145-158

21. Tyrer J, Duffy SW, Cuzick J (2004) A breast cancer prediction model incorporating familial and personal risk factors. Stat Med 23(7):1111-1130

22. Antoniou AC, Pharoah PP, Smith P, Easton DF (2004) The BOADICEA model of genetic susceptibility to breast and ovarian cancer. Br J Cancer 91(8):1580-1590

23. Antoniou AC, Cunningham AP, Peto J, Evans DG, Lalloo F, Narod SA et al (2008) The BOADICEA model of genetic susceptibility to breast and ovarian cancers: updates and extensions. $\mathrm{Br}$ J Cancer 98(8): 1457-1466

24. Mavaddat N, Rebbeck TR, Lakhani SR, Easton DF, Antoniou AC (2010) Incorporating tumour pathology information into breast cancer risk prediction algorithms. Breast Cancer Res 12(3):R28

25. Lee AJ, Cunningham AP, Kuchenbaecker KB, Mavaddat N, Easton DF, Antoniou AC et al (2014) BOADICEA breast cancer risk prediction model: updates to cancer incidences, tumour pathology and web interface. Br J Cancer 110(2):535-545

26. Lee AJ, Cunningham AP, Tischkowitz M, Simard J, Pharoah PD, Easton DF et al (2016) Incorporating truncating variants in PALB2, CHEK2, and ATM into the BOADICEA breast cancer risk model. Genet Med 18(12):1190-1198

27. Darabi H, Czene K, Zhao W, Liu J, Hall P, Humphreys K (2012) Breast cancer risk prediction and individualised screening based on common genetic variation and breast density measurement. Breast Cancer Res 14(1):R25

28. Lee A, Mavaddat N, Wilcox AN, Cunningham AP, Carver T, Hartley S et al (2019) BOADICEA: a comprehensive breast cancer risk prediction model incorporating genetic and nongenetic risk factors. Genet Med 21(8):1708-1718

29. Pal Choudhury P, Wilcox AN, Brook MN, Zhang Y, Ahearn T, Orr $\mathrm{N}$ et al (2020) Comparative validation of breast cancer risk prediction models and projections for future risk stratification. J Natl Cancer Inst 112(3):278-285

30. Evans DGR, Harkness EF, Brentnall AR, van Veen EM, Astley SM, Byers H et al (2019) Breast cancer pathology and stage are better predicted by risk stratification models that include mammographic density and common genetic variants. Breast Cancer Res Treat 176(1):141-148

31. Arthur RS, Wang T, Xue X, Kamensky V, Rohan TE (2020) Genetic factors, adherence to healthy lifestyle behavior, and risk of invasive breast cancer among women in the UK Biobank. J Natl Cancer Inst 112(9):893-901

32. Eisinger F, Reynier CJ, Chabal F, Luquet C, Moatti JP, Sobol H (1997) Acceptable strategies for dealing with hereditary breast/ ovarian cancer risk. J Natl Cancer Inst 89(10):731

33. Vachon CM, Schaid DJ, Ingle JN, Wickerham DL, Kubo M, Mushiroda T et al (2015) A polygenic risk score for breast cancer in women receiving tamoxifen or raloxifene on NSABP P-1 and P-2. Breast Cancer Res Treat 149(2):517-523
34. Easton DF, Pooley KA, Dunning AM, Pharoah PD, Thompson D, Ballinger DG et al (2007) Genome-wide association study identifies novel breast cancer susceptibility loci. Nature 447(7148):1087-1093

35. Michailidou K, Hall P, Gonzalez-Neira A, Ghoussaini M, Dennis J, Milne RL et al (2013) Large-scale genotyping identifies 41 new loci associated with breast cancer risk. Nat Genet 45(4):353-361

36. Shieh Y, Hu D, Ma L, Huntsman S, Gard CC, Leung JW et al (2016) Breast cancer risk prediction using a clinical risk model and polygenic risk score. Breast Cancer Res Treat 159(3):513-525

37. Ziv E, Tice JA, Sprague B, Vachon CM, Cummings SR, Kerlikowske K (2017) Using breast cancer risk associated polymorphisms to identify women for breast cancer chemoprevention. PLoS ONE 12(1):e0168601

38. Vachon CM, Scott CG, Tamimi RM, Thompson DJ, Fasching PA, Stone J et al (2019) Joint association of mammographic density adjusted for age and body mass index and polygenic risk score with breast cancer risk. Breast Cancer Res 21(1):68

39. Dartois L, Gauthier É, Heitzmann J, Baglietto L, Michiels S, Mesrine $S$ et al (2015) A comparison between different prediction models for invasive breast cancer occurrence in the French E3N cohort. Breast Cancer Res Treat 150(2):415-426

40. Gauthier E, Brisson L, Lenca P, Ragusa S (2011) Breast cancer risk score: a data mining approach to improve readability. In: Proceedings of the 2011 international conference on data mining, July 18-21, 2011, Las Vegas, Nevada, USA. CSREA Press: Athens, pp $15-21$

41. Gauthier E, Brisson L, Lenca P, Clavel-Chapelon F, Ragusa S (2012) Challenges to building a platform for a breast cancer risk score. In: Sixth international conference on research challenges in information science, May 16-18, 2012, Valencia, Spain. Curran Associates: Red Hood, pp 1-10

42. Gauthier E, Tice JA, Michiels S, Kaufmanis A, Drubay D, Brixi $\mathrm{Z}$ et al (2017) Breast cancer risk prediction by a machine learning model versus the BCSC score: performances on the US Breast Cancer Screening Consortium and a French screening cohort. Cancer Res 77(4 Supplement):P2-06-05-P2-06-05. https://doi. org/10.1158/1538-7445.SABCS16-P2-06-05

43. Horizon 2020 (2019) MyPeBS. International randomized study comparing personalized, risk-stratified to standard breast cancer screening in women aged 40-70. https://cordis.europa.eu/project/ $\mathrm{rcn} / 212694 /$ factsheet/en. Accessed 7 July 2021

44. Balleyguier C, Arfi-Rouche J, Boyer B, Gauthier E, Helin V, Loshkajian A et al (2019) A new automated method to evaluate 2D mammographic breast density according to BI-RADS® atlas fifth edition recommendations. Eur Radiol 29(7):3830-3838

45. Owens DK, Davidson KW, Krist AH, Barry MJ, Cabana M, Caughey AB et al (2019) Medication use to reduce risk of breast cancer: US preventive services task force recommendation statement. JAMA 322(9):857-867

46. Veron L, El-Mouhebb M, Annerose-Zephir G et al (2018) Feasibility of breast cancer risk assessment and personal recommendations delivery in community practice: a national prospective study. Eur J Cancer 92(Suppl 3):S50-51

47. Uzan $C$, Ndiaye-Guèye D, Nikpayam M, Cheikh EOE, Lebègue $\mathrm{G}$, Canlorbe $\mathrm{G}$ et al (2020) First results of a breast cancer risk assessment and management consultation. Bull Cancer 107(10):972-981

48. Ho WK, Tan MM, Mavaddat N, Tai MC, Mariapun S, Li J et al (2020) European polygenic risk score for prediction of breast cancer shows similar performance in Asian women. Nat Commun 11(1):3833

49. Wen W, Shu XO, Guo X, Cai Q, Long J, Bolla MK et al (2016) Prediction of breast cancer risk based on common genetic variants in women of East Asian ancestry. Breast Cancer Res 18(1):124 
50. Du Z, Gao G, Adedokun B, Ahearn T, Lunetta KL, Zirpoli G et al (2021) Evaluating polygenic risk scores for breast cancer in women of African ancestry. J Natl Cancer Inst. https://doi.org/10. 1093/jnci/djab050

51. Antoniou A, Pharoah PD, Narod S, Risch HA, Eyfjord JE, Hopper JL et al (2003) Average risks of breast and ovarian cancer associated with BRCA1 or BRCA2 mutations detected in case Series unselected for family history: a combined analysis of 22 studies. Am J Hum Genet 72(5):1117-1130

52. Pujol P, Barberis M, Beer P, Friedman E, Piulats JM, Capoluongo ED et al (2021) Clinical practice guidelines for BRCA1 and BRCA2 genetic testing. Eur J Cancer 146:30-47
53. Esserman LJ, Investigators WSaA (2017) The WISDOM Study: breaking the deadlock in the breast cancer screening debate. NPJ Breast Cancer 3:34

54. https://www.genomequebec.com/211-en/project/personalizedrisk-assessment-for-prevention-and-early-detection-of-breastcancer-integration-and-implementation/

Publisher's Note Springer Nature remains neutral with regard to jurisdictional claims in published maps and institutional affiliations. 